\title{
Influence of the parameters of the layer of ore being brought down on its freezing and losses during the face ore draw
}

\author{
Vladimir Zubkov ${ }^{l}$, Dmitrii Petrov ${ }^{*}$, Dosanbai Bekbergenov ${ }^{2}$. \\ ${ }^{1}$ Mining Institute of the North, Siberian Branch, Russian Academy of Sciences, laboratory of \\ problems of rational development of mineral resources, 677980, 43 Lenina Ave., Yakutsk city, Russia \\ ${ }^{2}$ D.A. Kunaev mining institute, laboratory of comprehensive exploration of mineral resources, \\ 050046, 191 Abaia Ave., Almaty city, Republic of Kazakhstan
}

\begin{abstract}
Application of mining systems with ore caving and adjacent strata, which do not entail high expenditures on delivery of freed ore and rock pressure management, allows to considerably increase efficiency of underground mining of ore deposits in the cryolithic zone. However, their use where permafrost formations are prevalent, requires taking into account factors complicating mining operations, in particular, the congealing of broken ore in the stoping zone. In order to assess the impact of thermal and humidity conditions on the completeness of reserves recovery, a study was carried out to determine the dependence between the volume of losses of broken ore prone to congealing and the width and height of the layer being brought down. Experimental studies were conducted by physical simulation in a cryo chamber on a laboratory bench. The ore drawing was conducted in a uniform sequence at the temperature in the stoping zone of minus $5{ }^{\circ} \mathrm{C}$. The final parameter to be determined the loss of ore prone to congealing, was defined as the difference between the mass of ore in the block and the mass of ore drawn. It has been established that the losses of the broken ore due to congealing increase significantly when the depth of the layer being freed decreases and the width increases.

The established patterns of influence of parameters of a beaten layer on losses of ore mass will be used during development of recommendations on technology of drawing of ore mass prone to congealing in the negative thermal conditions of underground mines of a cryolithic zone. Key words: underground mining, cryolithic zone, caving, drawing, congealing, parameters of broken-up layer, ore losses.
\end{abstract}

\section{Introduction}

In case of underground mining of ore deposits of cryolithic zone, located in areas with underdeveloped transport and industrial infrastructure, application of systems with combined top slicing and ore caving is very promising due to their high productivity and minimal costs for maintenance of mined-out space.

*Corresponding author: petrovdn74@mail.ru 
However, underground development of deposits located in the cryolithic zone requires taking into account climatic, mining and geological conditions, which have a serious negative impact on all mining processes. One of such factors is the possibility of freed ore congealing in the stoping zone, which may lead not only to unreasonably high losses of ore, but also to an emergency shutdown of the whole mining process.

In spite of the fact that the instances of broken ore congealing when drawn were recorded, for example, at Nezhdaninsky mine in the $80 \mathrm{~s}$ of the last century, there are very few studies that allow to assess the dynamics of this phenomenon and its impact on the extraction rates when drawing the ore. The purpose of the work was to determine the regularities of ore loss due to congealing, at different parameters of the broken-up layer (width, depth) and humidity of the broken-up rock mass, which is necessary for the development of recommendations on the technology of ore drawing under the negative thermal conditions of underground mines of cryolithic zone.

\section{Experimental research technique}

The sublevel caving version of development system with the layout of ore body cross-pitch rooms, applied at Nezhdaninsky mine when mining ore bodies with width of $15 \mathrm{~m}$ and more $[1,2]$ was chosen as a full-scale test subject in the course of this work.

The technique of physical modeling of ore drawing process, which takes into account the influence of parameters of the broken-up layer (depth, thickness) on the extraction indices of a mineral prone to congealing, is based on the known principles of similarity theory, modeling techniques and results of previous studies [3-9].

Optimal geometrical scale of $C_{L}$ similarity is defined from the expression

$$
C_{L}=L_{\mathrm{H}} / L_{\mathrm{M}}=50,
$$

where $L_{\mathrm{H}}$ and $L_{\mathrm{M}}$ are linear dimensions in natural conditions and in the model, respectively.

Since the acceleration of gravity in nature and on the model is the same, the scale of simulation the accelerations $C_{a}$ is set to 1 .

Based on the fact that the scale of simulation of accelerations

time simulation scale $C_{t}$ is calculated

$$
C_{a}=C_{L} / C_{t}^{2}
$$

$$
C_{t}=\sqrt{C_{L} / C_{a}}=\sqrt{50 / 1} \approx 7 .
$$

When using natural materials, the stresses of gravity are reduced in the model relative to the natural conditions in proportion to the linear scale, and the strength of the material is not reduced; therefore, the dynamic similarity is disrupted. But at the same time, according to V.R. Imenitov [5], the influence of stress reduction in the model, in comparison with nature, is compensated by a corresponding decrease in the adhesion factor of a granular material, and simulation of ore drawing in the field of gravity is theoretically possible at any volume weight of an equivalent material. To ensure compliance with the geometric similarity of motion it is sufficient to exclude from the material silt with a diameter less than $1 \mathrm{~mm}[6]$.

In addition, during the sublevel ore caving its intensity depends mainly on the productivity of the used loading and delivery machines, and the adfreezing strength of the material cannot be measured, therefore the disturbance of the dynamic similarity can be ignored.

The thermodynamic characteristics of the material of the model and the prototype were set to be fixed and equal. The temperature of the mine air, broken ore and broken down overlying rock in the model is assumed to be $-5.0^{\circ} \mathrm{C}$, meaning equal to the temperature in 
natural conditions. The equality of heat and temperature conductivity of ore and rock in natural and laboratory conditions was ensured by the use of natural materials. The temperature of water for ore material moistening in the model was set equal to $+3 \ldots+5{ }^{\circ} \mathrm{C}$ that also corresponds to its temperature in natural conditions.

A stand for physical simulation of the sublevel caving of ore from the block was designed and manufactured in accordance with the adopted research methodology. The stand is a prism-shaped structure consisting of two side walls, two end walls, a bottom and a drawing passage in the end wall in the form of a rectangular hole with side walls securely fixed to a solid base, and a gate board. For visual observation one side and front walls have been made of transparent plastic, the second side and back walls - of multilayer plywood, the bottom - of chipboard sheet. The walls of the stand and the drawing passage are fixed together by metal brackets and fastened to the bottom of the stand. To separate ore and rock, the stand has a vertical retractable slide with stops to adjust the thickness of the broken ore layer.

When modeling the sublevel caving of the layer, marble aggregate was taken as ore, and jaspilite as adjacent strata, the latter allowing the use of magnetic separation to separate the conventional ore and adjacent strata when determining the limit dilution in the drawing rate. Coarseness of grading of the applied material was the following: diameter of crushed ore pieces $\leq 5 \mathrm{~mm}$; enclosing rocks $\leq 15 \mathrm{~mm}$.

The placement of the material in the stand and the experimental ore drawing were carried out in a $30 \mathrm{~m}^{3}$ cryo chamber equipped with Polaris medium-temperature splitsystem. The required coarseness of grading was provided by screening for the required diameter using geological sieves. The crushed ore and the rock were placed in separate plastic containers, weighed to the accuracy of 1 gram and held in a cryo chamber with a steady temperature of minus $5{ }^{\circ} \mathrm{C}$ for 3 hours. Then, control temperature measurement of crushed ore and rock was carried out using a non-contact thermometer "Raynger ST20" and finely dispersed irrigation with simultaneous intensive mixing of ore material. Ore was moistened in the amount of $0.5 \ldots 1 \%$ of its mass, since previous studies have found that the specified interval is the most dangerous with respect to rock coagulating under the given freezing conditions.

Ore and rock material was placed in layers of $100 \mathrm{~mm}$ height. The required volume of ore was provided by installing a slide gate, which was extracted when the required volume of ore was filled.

After filling up to the required volume, the stands were kept stationary for 9 minutes, which, if the scale of kinematic similarity is observed, corresponds to the time of broken ore being stationary in natural conditions (interchange break used for ventilation), equal to 1 hour.

Then the sublevel carving of ore was conducted at the stand in the following order.

Ore in the amount of $50 \mathrm{~g}$ was raked out with a metal blade through the drawing passage of the stand and weighed. Then the chats were separated by magnetic separation and the remaining rock weighed. The time gap between drawing operations was calculated as the duration of the delivery cycle on a scale.

The sublevel carving was carried out until the limit dilution in the drawing rate reached $50 \%$.

After completion of the drawing, control tanks with ore mass and rock were weighed on the scales with an accuracy of 1 gram. After weighing, losses and dilution were measured by weight.

All data obtained during the experiment were recorded in the parameter log.

The measurement results were processed in three stages. During the first stage, the data of individual experimental drawings was processed. The second stage involved grouping and generalization of the results to define extraction parameters for each layer parameter 
separately. At the third stage, generalizing tables with test results were compiled and dependency graphs were constructed.

\section{Results and discussion}

The main results obtained are presented in the form of graphs describing the change of ore loss indicators due to congealing depending on the parameters of the broken layer (width, height) and moisture levels of the broken rock mass (Fig. 1).

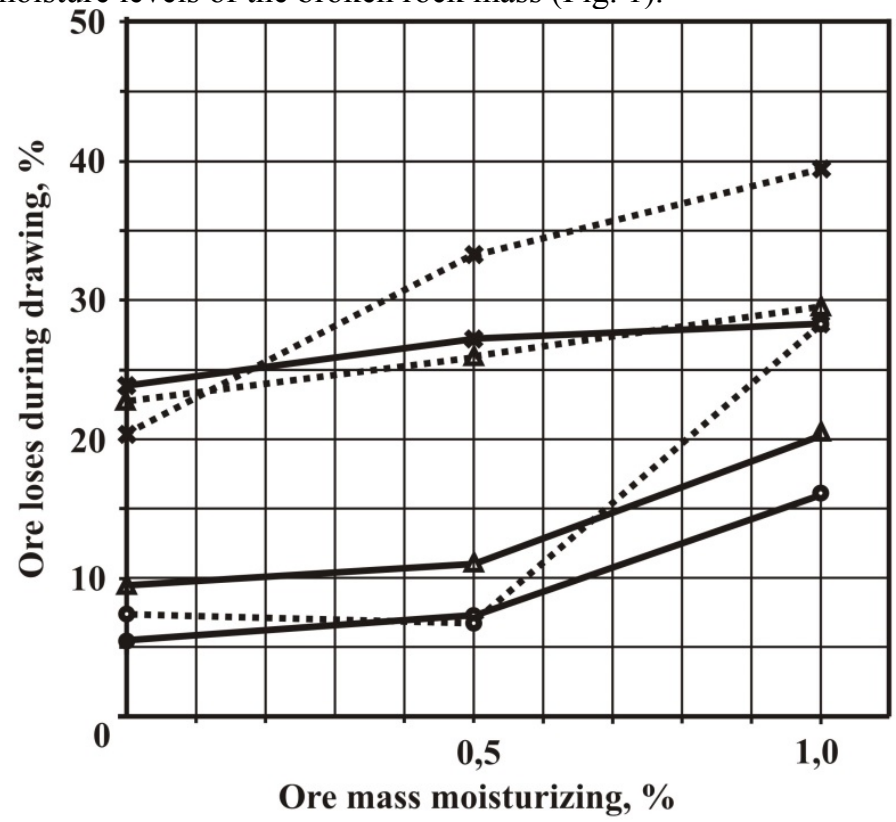

Explanation of symbol

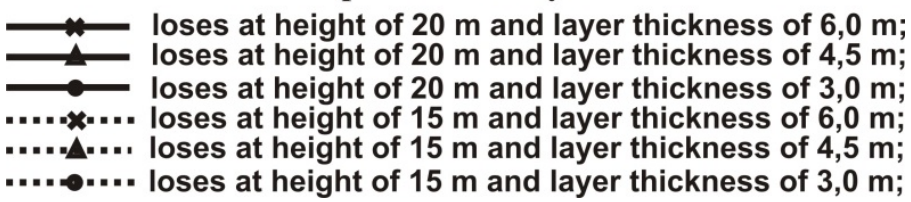

Fig. 1. Influence of changes in the height of sublevel, thickness of the broken layer and the degree of moisture on the ore mass losses during drawing due to its congelation at minus $5{ }^{\circ} \mathrm{C}$

The following data were obtained as a result of conducted experimental studies:

1. It has been established that when the moisture content of ore increases from 0 to 1 $\%$ and the height of the broken layer decreases from 20 to $15 \mathrm{~m}$, the loss of ore during drawing due to its congelation increases by $21 \%$.

2. The change in the thickness of the broken layer from 3 to $6 \mathrm{~m}$ under similar conditions $(0 \ldots 1 \%$ ore moisture $)$ also affects the increase of ore losses during drawing, which is $9 \%$ on average.

The main reason for the increase in losses due to congealing when the height of sublevel decreases is the increase in relative losses from changes in the parameters of the drawing figure. The increase in the volume of fixed ore leads to an increase in the volume of congealed ore at the borders of the drawing figure.

When the moisture content of ore material increased from 0.5 to $1.0 \%$, there were recorded short-term unstable overhangs of ore during drawing caused by it congealing. This 
fact confirms the conclusion obtained by previous studies that the specified moisture interval is critical for rocks congealing.

\section{Conclusions}

Experimental studies have established the nature of change in the indicators of completeness of extraction of ore, prone to re-congelation, in the system of combined top slicing and ore caving, depending on the adopted height and thickness of the broken layer. Undoubtedly, the data obtained are valid only for the conditions of a specific experiment, but it allows us to estimate the possibility of reducing the volume of losses of broken ore caused by congealing in the stoping zone by choosing the optimal parameters of the broken layer (height and thickness).

The results of this study may serve as a basis for development of recommendations on ore drawing technology under the negative thermal conditions of underground cryolithic mines.

\section{References}

1. V.M. Bakhmutov, Technological regulations for the development of a technical project for Nezhdaninskiy GOK in the Yakut ASSR on the technology of underground mining (Chita: CHF VNIPIGortsvetmet, 1986)

2. S.V. Artemonov [and others], Development of an effective technology for mining ore bodies at the Nezhdaninskoe deposit: Research report (GIPROTSVETMET; Chita, 1989)

3. V.I. Bashkov, A.I. Kopytov, Vestnik of Kuzbass State Technical University, 2, 75 $-77,(2015)$

4. A.A. Leontev, Iu. V. Demidov, V. V. Belousov, Mining informational and analytical bulletin 7, 48-55, (2012)

5. V.R. Imenitov, I. A. Kovalev, V. S. Uralov, Simulation of the caving and ore drawing (Moscow, MGI, 1961)

6. I.N. Savich, D. K. Zenko, Mining informational and analytical bulletin 4, 219221, (2004)

7. A.M. Mazhitov, E. Yu. Meshchriakov, Vestnik of Nosov Magnitogorsk State Technical University, 2, 5-8, (2013)

8. G.V. Shubin, D. I. Kiriushin, V.S. Sorokin, B.N. Zarovniaev, A.M. Alekseev, Mining informational and analytical bulletin 3, 153-160, (2012)

9. V.I. Mustafin, Rationale for the parameters of sublevel ore caving at the two-deck layout of the drill haulage workings: Diss. ... Cand. of Sciences (Moscow, National Research Technological University "MISIS", 2015) 